\title{
Inappropriate publication of trial results and potential for allegations of illegal share dealing
}

\author{
D S Freestone, H Mitchell
}

There is increasing evidence of fraud in clinical research, and one aspect concerns trading in pharmaceutical company shares by people who may have confidential information about the results of clinical trials. Plainly this has implications for honest investigators, who may find themselves exposed to such allegations. In this paper Dr D S Freestone and Mr H Mitchell, QC, identify three interlinked issues which they think underlie the potential for these allegations. They are pressure for premature or inappropriate communication of research results; trading in pharmaceutical company shares by academic clinical investigators; and the possibility that clinical investigators might succumb to temptation.

Dr Freestone and Mr Mitchell suggest that whenever possible results of clinical studies should be published in appropriate medical journals without prior public disclosure. This conflicts with Stock Exchange rules, which require that price sensitive information should be published at the earliest opportunity and preclude priority of publication in medical journals. Freestone and Mitchell believe that rarely rapid public disclosure is acceptable if it is to protect patients' interests but that it must not prejudice publication in the medical or scientific press. When rapid public disclosure is needed, they say, every attempt should be made to inform prescribers before patients.

Dr Freestone and Mr Mitchell warn that academic clinical investigators who have access to unpublished price sensitive information about pharmaceutical companies whose shares they trade in will almost certainly be in breach of the Company Securities (Insider Dealing) Act 1985. Furthermore, disclosing such information to third parties, they say, exposes those people also to potential criminal liability.

Freestone and Mitchell advise that when potential for allegations of conflict of interest exists clinical investigators should consider declaring their position to ethics committees and any sponsoring organisations.

The main parts of the clinical work in developing new medicines are conducted not by pharmaceutical companies but by academic clinicians with special skills and experience in managing patients suffering from conditions for which the new medicines may be beneficial. The honesty and integrity of clinicians and their independence of pharmaceutical companies should assure unbiased results.

Clinicians conduct studies of potential new medicines for various reasons-in anticipation of benefit for their patients; to contribute to advances in medical treatment; because publication brings prestige to themselves, their staff, and their departments; for the financial support participation brings in hard times; to bring in the longer term, high quality applicants to posts in their departments; and for the opportunities for meetings with leaders in other countries and for visits abroad to present results. These are accepted as the legitimate benefits of skills, experience, and energy. However, rarely investigators may yield to temptation: they may enter patients into studies when they have only borderline acceptance criteria; they may fabricate results; they may induce patients to enter trials for remuneration or better medical care..$^{1-4}$

This paper addresses three additional, interlinked issues - namely, premature or inappropriate publication of clinical trial findings; the potential for allegations of illegal share dealing against academic investigators who with unpublished share price sensitive information could gain improper financial rewards by trading in the shares of pharmaceutical companies for whom they are conducting clinical research; and the possibility that a clinical investigator may be tempted to change or manipulate clinical trial results to have a false effect on a company's share value.

\section{Premature or inappropriate publication}

Stock Exchange rules require that price sensitive information should be published at the earliest date and preclude priority of publication by specialist journals. However, in medicine it is accepted international practice that the results of research should be communicated through publication in journals to provide for peer review. This protects the community against premature disclosures in lay media, which are inevitably brief and may be sensationalised, biased, or unbalanced. Furthermore, the newsworthiness of scientific journals and indirectly the credibility of authors are preserved. Communication of the results of clinical research should properly follow this principle, as recognised in the Ingelfinger rules. ${ }^{5-7}$

The convention may need to be set aside should issues of public health importance arise which require early release of information. Examples include newly apparent hazards or benefits of medicines or other data which have a major influence on patient management. These occurrences are rare and any public pronouncements in advance of scientific publication need to be considered extremely carefully. Clearly priority and prestige are the wrong reasons for statements before publication. Any statements should be balanced, precise, and not open to misinterpretation. Ideally, no public statement should be made until a report suitable for publication in a medical or scientific journal is available from which a public statement can be derived. ${ }^{8}$ Discussing the circumstances with the editor of the journal in which publication is intended would be prudent. ${ }^{9}$

\section{Getting information to prescribers first}

In the United Kingdom in the past there have been protests from doctors at the lack of advance information about public statements by the Department of Health and the pharmaceutical industry concerning the safety of medicines. These have resulted in anxious patients seeking advice from their doctors who have not been properly informed. In these circumstances doctors inevitably find themselves disadvantaged and their ability to care for their patients is impaired. In general, medical departments of pharmaceutical companies go to great lengths to try to ensure that information gets to prescribers first. However, two factors have emerged which militate against this.

Firstly, patient representative groups in some
Ashtead, Surrey

$B M \mathcal{F} 1993 ; 306: 1112-4$
BMJ VOLUME 306

24 APRIL 1993 


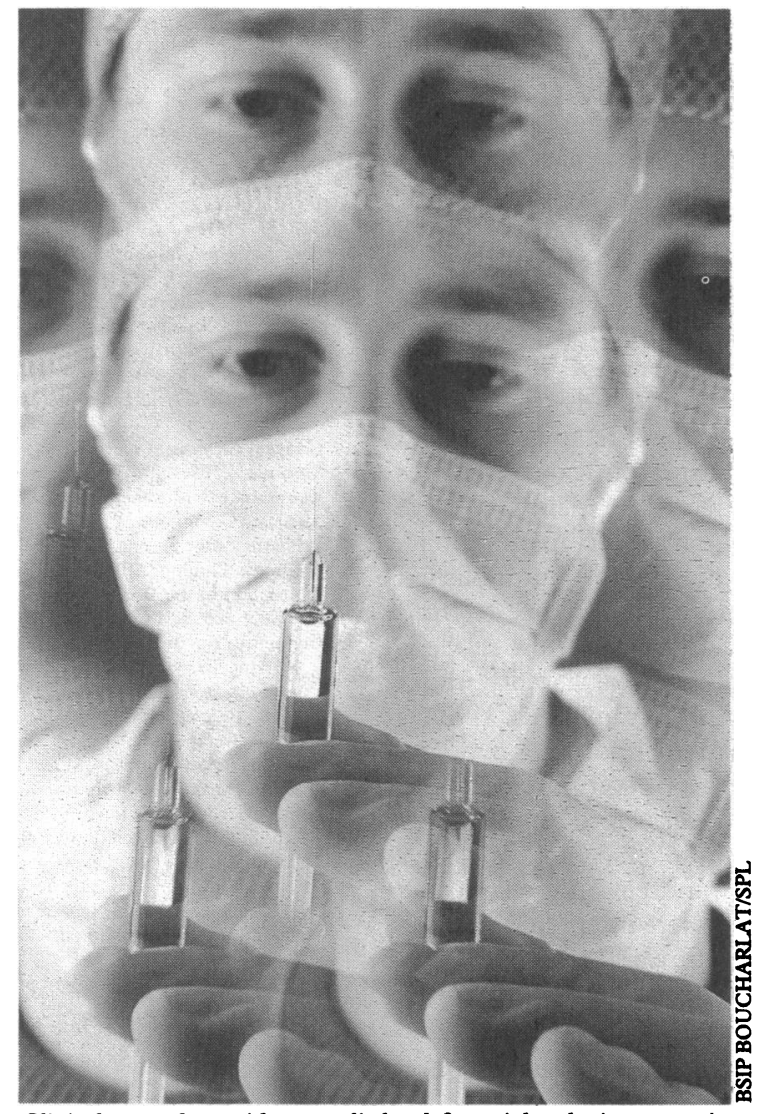

Clinical researchers with an undisclosed financial stake in companies whose products they are evaluating may be accused of having a conflict of interest

branches of medicine are now so organised that they may immediately be aware that a clinical trial is to be stopped and in cooperation with the media require at once a public statement giving the results and the implications for patients. Secondly; the Company Securities (Insider Dealing) Act $1985^{10}$ was set up to ensure that company employees and others connected with the company do not profit from trading in that company's shares through access to unpublished price sensitive information. Stock Exchange rules do not allow for rapid confidential dissemination of unpublished information to clinical investigators or relevant medical specialists. The sensitivity of this matter is illustrated by the concerns expressed over copies of medical journals getting into the hands of financial analysts before publication. ${ }^{11}{ }^{12}$

Prosecutions for insider dealing have so far been rare. There has been no documented example of a clinical investigator profiteering in a pharmaceutical company's shares as a consequence of possessing unpublished price sensitive information, and the extent of any malpractice is not known. The difficulties are resolved by making the information public, but unfortunately the ability of the media to communicate information-sometimes incorrectly-is much greater and more rapid than that of individual pharmaceutical companies. Making information public almost ensures that many patients will get some information before their prescribers. Patients are poorly served by these arrangements. We need to find a method that will release price sensitive information to prescribers in advance of public disclosure. Greater awareness of the issues and debate are needed.

\section{Clinical researchers and Company Securities Act}

The Company Securities (Insider Dealing) Act 1985 (section 1 (1)) prohibits an individual connected with a company from dealing on a recognised stock exchange in securities of that company if he or she knowingly has unpublished price sensitive information in relation to those securities. Section 1 (2) of the act prohibits an individual from dealing in the securities of another company if by virtue of his or her connection with the first company he or she has unpublished price sensitive information in relation to the securities of that other company. An individual connected with a company is defined in section 9 of the act to include anyone having a professional or business relationship with the company.

Whether a clinical investigator would fall within the definition of an "individual connected with" a company has not been tested in law. However, in our view a clinical investigator who buys or sells shares in a pharmaceutical company while in possession of unpublished price sensitive information pertaining to the effectiveness or safety of a licensed or unlicensed medicine of that company could be committing an offence under the act. Whether or not unpublished information is price sensitive needs careful consideration. For example, information which led to the withdrawal of a minor product with sales of a few thousand pounds by a multimillion pound turnover company and without other overtones is unlikely to be price sensitive. By contrast, clinical research results which signal a breakthrough in treatment, support product registration, and lead to worldwide use of a new product yielding thousands of millions of pounds in cumulative revenues are very likely to be price sensitive. Determining whether individual clinical research results are price sensitive may be difficult and requires careful judgment.

\section{Actions taken to limit malpractice}

Clearly, falsifying or manipulating clinical trial results to create a false market in a pharmaceutical company's shares would be dishonest, might constitute obtaining pecuniary advantage by deception under the Theft Act 1968, and might lead to the clinical investigator being referred to the General Medical Council charged with serious professional misconduct. ${ }^{13}$ Published guidelines are designed to detect and limit such malpractice. ${ }^{14} 15$

In the United States the organisers of the postcoronary artery bypass graft study decreed that clinical investigators and their spouses and dependants should not buy, sell, or hold stock or stock options in any company providing or distributing medicines under study. The decree applied from the time of recruiting the first patient until funding for the study in the investigators' unit ended and the results had been made public or the investigators' involvement in the study ended. ${ }^{16}$ Similarly, the National Institutes of Health have circulated for comment guidelines which would bar clinical investigators (and their immediate family members) from equity holdings or options in any company that would be affected by the outcome of research or supplying a product or equipment being evaluated in the research project. ${ }^{1718}$ Pressures for similar action are evident in the United States Public Health Service. ${ }^{19}$ Journal editors may require authors to identify any relevant financial interests. ${ }^{2021}$ Some regard these rules as draconian..$^{22}$

The requirement that someone who bought shares, possibly for long term investment, should sell them at a disadvantageous time because an experienced clinical investigator who is an immediate relative has accepted an invitation to participate in a study is oppressive. Equally, it is not in society's interest that experienced clinical investigators should be excluded from such studies because of share ownership. Certainly if external investigators are not to be at risk of allegations of illegal share dealing they would be wise not to buy or sell shares in the companies whose products are the 
subject of their research. Neither should they buy or sell shares in any other company whose share price might be affected by the results of their research from the time the research starts until results are made public. Clinical studies may last several years.

\section{Proposed guidelines}

Academic clinical investigators generally need to be more familiar with the issues concerned in owning and trading in pharmaceutical companies' shares. We offer the following guidelines and advice. Clinical investigators (and their immediate relatives) should not buy or sell shares in pharmaceutical companies whose share price might be affected by their work until this is completed and results have been made public. Clinical investigators should not disclose unpublished price sensitive results of studies in confidence to third parties. Anyone to whom such disclosures are made is subject to the same potential criminal liability under the Company Securities (Insider Dealing) Act 1985 as the person from whom they had the information.

Clinical investigators, ethics committees, and research institutions might feel more comfortable if clinical investigators were to make a voluntary declaration to study ethics committees and to sponsors of any shareholdings for which there might be a conflict of interest and undertake not to trade in the relevant company's securities until the studies are completed and the results made public.
The views expressed in this paper are not necessarily those of Wellcome.

1 Lock S. Misconduct in medical research, does it exist in Britain? BMf 1988;297:1531-5.

2 Lock S. Research fraud, discouraging others. BMF 1990;301:1348.

3 Royal College of Physicians. Fraud and misconduct in medical research. London: RCP, 1991.

4 New issues on US scientific misconduct. Scrip 1989; No 1425:19.

5 Relman AS. The Ingelfinger rule. $N$ Engl I Med 1981;305:824-6.

6 Relman AS. More on the Ingelfinger rule. $N$ Engl f Med 1988;318:1125-6.

7 Angell $\mathrm{M}$, Kassirer JP. The Ingelfinger rule revisited. $N$ Engl $f \mathrm{Med}$ 1991;325:1371-3

8 NCI guidelines for early release of data. Scrip 1990; No 1574:22.

9 Smith J. Sudden infant death syndrome and the media. BMF 1989;298: 1601-2.

10 Company Securities (Insider Dealing) Act 1985. London: HMSO, 1985.

11 Stockmarket use of BMJ report investigated. Scrip 1989; No 1381:5.

12 Use of share sensitive reports debated. Scrip 1989; No 1382:2.

13 Medical Committee Working Party of the Association of the British Pharmaceutical Industry. Fraud and malpractice in the context of clinical research. London: ABPI, 1992.

14 Association of the British Pharmaceutical Industry. Guidelines on good clinical research practice. London: ABPI, 1988.

15 Committee for Proprietary Medicinal Products of the European Community Working Party on Efficacy of Medical Products. Good clinical practice for trials on medicinal products in the European Community. Brussels: WPEMP, 1988. (Reference 111/3976/88.)

16 Healy B, Campeau L, Gray R, Herd A, Hoogwerf B, Hunninghake D, et al. Special report. Conflict-of-interest for a multicenter clinical trial of treatmen after coronary-artery bypass-graft surgery. N Engl f Med 1989;320:949-51.

17 NIH's strict conflict of interest. Scrip 1989; No 1466:20.

18 US conflict of interest guidelines. Scrip 1989; No 1383:18.

19 US rules needed for conflict of interest? Scrip 1990; No 1557:18.

20 Sibbison J. Protecting the integrity of research. Lancet 1989;ii:1094.

21 Lundberg GD, Flanagin A. New requirements for authors. Signed statements

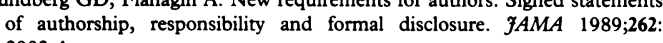
2003-4.

22 Second US conflict of interest proposal. Scrip 1990;No 1576:13.

(Accepted 9 February 1993)

\title{
For Debate
}

\section{Gall stones: the real issues}

\author{
Alan G Johnson
}

Over the past two years there has been enormous interest in laparoscopic techniques and millions of pounds have been invested in the design and manufacture of more and more advanced instruments for performing an operation that surgeons have been doing for the past 100 years-that is, removing the gall bladder for gall stones. We welcome, and await with interest, the results of the few randomised controlled trials that have been set up to assess the advantages of the new technique as applied to unselected patients and the possible savings (if any) when all costs and safety are included. I am, however, less concerned by the lack of proper data on these matters than by the frightening way in which commercial and technical interest has diverted attention from the two really important questions in gall stone disease. Both are far more relevant to the health service than the question of which technique to use. Why do gall stones form at all and how may they be prevented? And how many of the 40000-50000 patients a year who undergo cholecystectomy actually need their operations or gain overall health benefits from them?

University Surgical Unit, Royal Hallamshire Hospital, Sheffield S10 2JF A G Johnson, professor of surgery

BMF 1993;306:1114-5
Rolls-Royce or a Ford ambulance. It is far more relevant to ask how near we are to building a fence at the cliff edge and how many people on the beach are in fact happily playing in the sand, in no danger and not needing rescue! If the money that has been spent on new techniques with lithotripters and laparoscopes had been put into research on the cause and prevention of

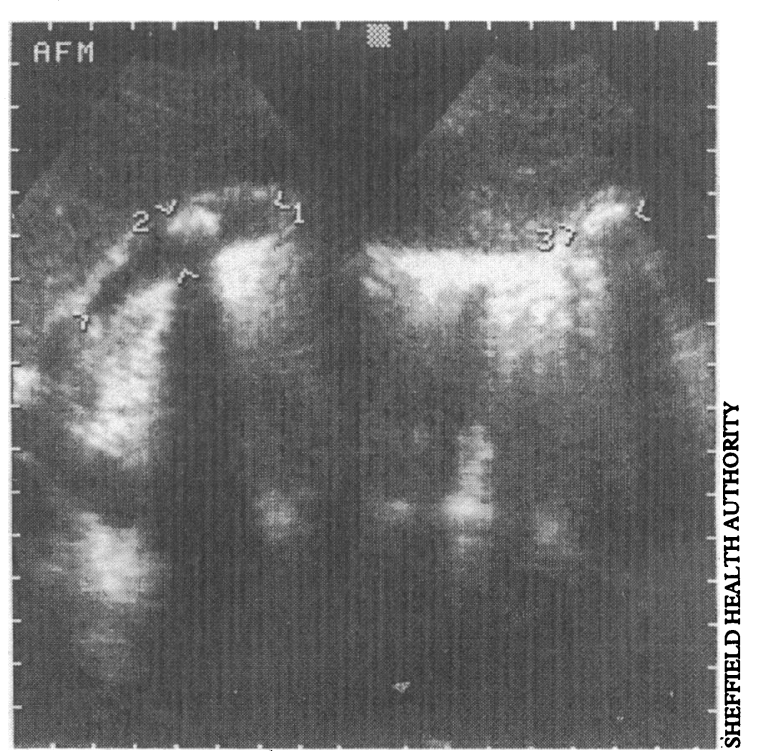

Ultrasonic image of gall bladder containing stone and contracting (right hand side) after fatty meal 